\title{
Comparison between insufflation with air or carbon dioxide during the colonoscopy in sedated patients with propofol
}

\author{
Pilar Díez-Redondo, Paula Gil-Simón, Noelia Alcaide-Suárez, Ramón Atienza-Sánchez, \\ Jesús Barrio-Andrés, Carlos de-la-Serna-Higuera and Manuel Pérez-Miranda \\ Department of Digestive Diseases. Hospital Universitario "Río Hortega". Valladolid. Spain
}

\begin{abstract}
Objectives: compare the intensity of pain experienced after colonoscopy with air or with $\mathrm{CO}_{2}$ and evaluate the safety of $\mathrm{CO}_{2}$ in colonoscopies performed with moderate/deep sedation.

Materials and methods: individuals undergoing ambulatory colonoscopy without exclusion criteria (severe respiratory disease, morbid obesity) were randomized in air or $\mathrm{CO}_{2}$ group. We recorded different variables prior to, during and upon completion of the colonoscopy, performing monitoring using pulse oximetry and capnography. Each patient rated, using a visual numeric scale, the intensity of post-colonoscopy pain at different moments.

Results: 141 individuals in the air group (sex M/F 63/78, age 24-83) and the $\mathrm{CO}_{2}$ group (sex M/F 59/70, age 24-82). No significant differences existed in the recorded variables in both groups except for the greater number of explorations performed by an endoscopist in training (TE) in the air group compared to those by a more experienced endoscopist (SE). $\mathrm{CO}_{2}$ in expired air, episodes of oxygen desaturation and of apnoea and dose of propofol, of midazolam were similar in both groups. No episodes of hypercapnea or any complication requiring cardiopulmonary resuscitation measures were recorded. The pain in the air group was significantly higher at 15 minutes and at 1, 3 and 6 hours after the endoscopy, equalising at 24 hours. After multivariant adjustment for type of doctor (TE vs. SE) the differences observed in pain intensity for each group were maintained.

Conclusions: a) the use of $\mathrm{CO}_{2}$ in colonoscopy causes significantly less pain in the first 6 hours after the procedure; b) its use in patients with moderate/deep sedation is safe; and c) performance of the endoscopic technique is not modified, nor are times reduced.
\end{abstract}

Key words: $\mathrm{CO}_{2}$ Dioxide carbon. Painless colonoscopy. Propofol. Safety.

\section{INTRODUCTION}

Colonoscopy is currently the technique of choice for studying the pathology of the colon, playing an increasingly important role in the treatment of lesions found. Moreover, in recent years, colonoscopies have proved effective in the secondary prevention of colorectal cancer (CRC) (1).

The insufflation of the colon, usually with air, is an essential mechanism for achieving vision of the colonic wall during a colonoscopy. However, it contributes to the exploration can be painful for the patient, both during implementation and in the hours after, by causing bloating that lasts until most of the air has been removed. Other side effects of prolonged air insufflation, although rare, may be the explosion of the colon when making a therapeutic electrocautery (2), perforation (3), air embolism (4) or ischemia of fragment swelling from the obstruction of blood flow due to pressure on the vessels of the colonic wall (5). The $\mathrm{CO}_{2}$, due to a much greater water solubility than that of the gases that form the ambient air, presents a more rapid removal, after passing from the colon into the bloodstream, which is associated with less strain and abdominal pain during and after the colonoscopy (6-9) and less disturbance of parietal blood flow by its potencial vasodilative effect (10). Although theoretically the insufflations of the colon with $\mathrm{CO}_{2}$ insufflation may lead to increased blood retention and trigger a metabolic acidosis, there have not been any reported adverse respiratory effects during colonoscopies performed with $\mathrm{CO}_{2}$. Other aspects that should be evaluated are the impact of the use of $\mathrm{CO}_{2}$ could have on the development of the technique or sedation needs.

Díez Redondo P, Gil Simón P, Alcaide Suárez N, Atienza Sánchez $R$, Barrio Andrés J, De la Serna Higuera and Pérez-Miranda M. Comparison between insufflation with air or carbon dioxide during the colonoscopy in sedated patients with propofol. Rev Esp Enferm Dig 2012;104:411-417. 


\section{AIMS}

The objectives of this study were: a) compare the intensity of pain experienced by patients after undergoing a colonoscopy with ambient air or $\mathrm{CO}_{2}$; b) assess the safety of $\mathrm{CO}_{2}$ in colonoscopies performed with moderate-deep sedation with propofol in combination with midazolam; and c) analyze the potential impact of the use of $\mathrm{CO}_{2}$ in the development of the technique and the subsequent recovery of the patient.

\section{PATIENTS AND METHODS}

A randomized group of individuals over the age of 18 underwent a colonoscopy in the outpatient endoscopy unit of the . They were put into two groups (insufflation with air or $\mathrm{CO}_{2}$ ). A randomization list, generated by Epidat 3.1 software, was applied exclusively by the nurse in admission room, being helped by assistants in charge of preparing the source of insufflations. To calculate the appropriate sample size, we conducted a pilot study on 20 patients per group $\left(\right.$ air $\left./ \mathrm{CO}_{2}\right)$ and estimated that at 15 minutes, there was a 1.5 point difference in pain scores (estimated average: 3-point group air, $\mathrm{CO}_{2} 1.5$ points, 2.5 points combined standard deviation) for which we calculated a required sample of 45 subjects per group. The sample was expanded to 120 subjects to detect group differences in percentages between the groups for qualitative variables by $15 \%$. This included patients for six consecutive weeks, which agreed to participate in our study and did not submit the following exclusion criteria: severe respiratory illness (with hospitalization in the last 6 months or receiving home oxygen therapy), sleep apnea, morbid obesity, inability to understand the study, successive gastroscopy and colonoscopy or a sigmoidoscopy. All patients included in the study signed an informed consent form, which was previously approved by the Clinical Research Ethics Committee of our hospital. Neither the patients, the nurse nor the endoscopist who performed the examination knew which gas was being used for insufflation. The procedures were performed by six endoscopists who usually work in our unit and an endoscopist in training who was independent to perform the technique, all under sedation, controlled by the endoscopist using a combination of midazolam and propofol. No analgesics drugs, meperidine or similar types were used in patients. It was considered "mild sedation" of which the patients were awake, "moderate" when presented drowsiness but were able to respond appropriately to verbal stimuli, and "deep" when only respond to painful stimuli. Although was not used a validated colonic cleansing scale, we took into account the colonic preparation with a simplified form: "good" when there was no or scarce fecal matter or clear liquid allowing a proper assessment of the entire colon; "regular" when there remains semisolid stool but allowed the assessment of most of the colon and "bad" when the exploration was interrupted by a large amount of solid fecal matter that prevented adequate visualization.

We used colonoscopes Exera II CFH180AL from and insufflator $\mathrm{CO}_{2} \mathrm{UCR}$ (Endoscopic $\mathrm{CO}_{2}$ Regulation Unit Olympus, Japan) whose source of $\mathrm{CO}_{2}$ was supplied centrally from the pipes of the hospital building. Variables were collected before, during and after the colonoscopy, including the registration of $\mathrm{O}_{2}$ saturation values, $\mathrm{CO}_{2}$ concentration in expired air and heart rate (HR) by pulse oximetry and capnography with naso-oral cannula with a Philips monitor Intellivue MP 5. All patients received oxygen during the procedure, with initial doses of 2 liters per minute.

Subsequently, each patient scored the intensity of abdominal pain they felt after 15 minutes and after 1, 3, 6 and 24 hours following the completion of the colonoscopy. The scores were measured using a visual numeric scale (VNS) ranging from 0 "no pain" to 10 , "worst pain imaginable", and recorded the results through telephone. It was not determined the abdominal pain that patients could feel before or during endoscopic examination.

The collected data was statistically analyzed using SPSS (version 14.0, 2004 SPSS Inc., Chicago Ill., USA). Continuous variables were described as the mean \pm SD when normally distributed or as a median range if the distribution was not normal. Qualitative variables were described by absolute and relative frequencies (percentages). To study the association between variables the qualitative Chi-square test was used, and in the case of quantitative variables, the Kolmogorov-Smirnov test was used. To evaluate the differences between the independent means, parametric statistical tests or nonparametric, required by the conditions of application ( $\mathrm{t}$ de Student, U de Mann-Whitney) were used. The correlation between quantitative variables was performed using Pearson's test (normal distribution) or Spearman (not normal). Finally a multiple logistic regression was performed. The level of significance was considered at $\mathrm{p} " 0.05$.

\section{RESULTS}

In the study period, our unit performed a total of 365 outpatient colonoscopies, of which 67 were excluded from it: 35 because it was a colonoscopy after a gastroscopy or a sigmoidoscopy, six patients were unable to understand and cooperate with the study, six patients were affected by severe lung disease, four patients were morbidly obese, and the other 16 patients refused to participate in the trial. The remaining 298 patients were randomly separated into two groups, $\mathrm{CO}_{2}$ group and air group; however, 67 of patients did not have a final analysis: the colonic preparation was very poor in 10 patients preventing the procedure to be completed, in one patients because of the breach of "double blind" and we were not able to track 17 patients because in seven cases the patient required hospitalization from the findings in the colonoscopy, and the other 10 patients did not respond to the survey. In the end, 129 patients were 
Table I. Patients and explorations characteristics

\begin{tabular}{lccc}
\hline & Air & $\mathrm{CO}_{2}$ & $p$ value \\
\hline Age & $56.7(24-83$ years) & 56 (24-82 years) & 0.862 (NS) \\
Sex (M/F) & $63 / 78$ & $59 / 70$ & 0.772 (NS) \\
BMl & 26.6 & 26 & 0.860 (NS) \\
Abdominal surgery history & $39 \%$ & $32.6 \%$ & 0.270 (NS) \\
Colon surgery history & $4.6 \%$ & $4.2 \%$ & 0.886 (NS) \\
Colon cleanliness "good" & $78 \%$ & $75 \%$ & 0.780 (NS) \\
No pathological colonoscopy & $61.7 \%$ & $63.6 \%$ & 0.752 (NS) \\
Therapeutic & $32.2 \%$ & $26.4 \%$ & 0.380 (NS) \\
lleoscopy & $10.6 \%$ & $10.2 \%$ & 0.880 (NS) \\
\hline
\end{tabular}

BMI: body mass index; M/F: male/female; NS: not significant.

included in the $\mathrm{CO}_{2}$ group and 141 patients were included in the air group.

Both groups were comparable in mean age, sex, body mass index, history of abdominal surgery and a history of colon surgery. There was no significant difference in cleanliness of the colon between the groups. Both groups had about $75 \%$ cases that were rated good cleanliness and the number of polypectomies or ileoscopies perfomed was similar in both groups (Table I).

In order of frequency, with no difference between the groups, the reasons for the request of a colonoscopy were: rectal bleeding, CCR screening, post-polypectomy surveillance, bowel habit change, revision after CCR, chronic diarrhea, anemia, constipation, abdominal pain and others. Requests of a colonoscopy due to abdominal pain corresponded to approximately $2 \%$ of total in each group.

The level of sedation was similar in both groups: deep sedation in $74.5 \%$, moderate in $22.5 \%$ and superficial in $3 \%$ of the patients in the $\mathrm{CO}_{2}$ group, compared with $75 \%$ of deep sedation, $20.6 \%$ of moderate and $4.4 \%$ of superficial in the air group. The drugs used for sedation were midazolam and propofol, with almost equal mean doses $\left(\mathrm{CO}_{2}: 3 \mathrm{mg}\right.$ midazolam and $70 \mathrm{mg}$ of propofol / air: $3.16 \mathrm{mg}$ midazolam and propofol $69.8 \mathrm{mg}$ ). Patient's tolerance during the colonoscopy within the $\mathrm{CO}_{2}$ group was considered slightly better by endoscopists but not statistically significant. Neither the average time of cecum intubation, the total time nor patient stay in the recovery room after the colonoscopy showed differences (Table II). However, the percentage of examinations performed by an endoscopist in training (TE) compared to those performed by a senior endoscopist (SE) was significantly higher in the air group $(29 \% \mathrm{EF} / \mathrm{EE} 71 \%)$ than in the $\mathrm{CO}_{2}$ group ( $\mathrm{EF} 14 \% / 86 \% \mathrm{EF})(\mathrm{p}=0.003)$. At the beginning and end of the examination, all patients' values of $\mathrm{pO}_{2}, \mathrm{p} \mathrm{CO}_{2}$ and HR, as well as the most extreme values of these parameters and episodes of apnea that occurred during the procedure were collected. There were no significant differences between the groups in mean values of $\mathrm{pCO}_{2}$ or $\mathrm{pO}_{2}$. There were episodes of hypocapnia $\left(\mathrm{pCO}_{2}<30 \mathrm{mmHg}\right)$ in $51 \%$ of patients in the air group and in $46 \%$ of patients in the $\mathrm{CO}_{2}$ group ( $\mathrm{p}=0.205)$. A single episode of hypercapnia occurred in one patient in the $\mathrm{CO}_{2}$ group, $\mathrm{pCO}_{2}$ of $55 \mathrm{mmHg}$. As for the $\mathrm{pO}_{2}$, there were episodes of hypoxemia $\left(\mathrm{pO}_{2}<95 \%\right)$ in $19 \%$ of patients in the air group and in $24 \%$ of patients in the $\mathrm{CO}_{2}$ group $(\mathrm{p}=0.261)$. The percentage of episodes of apnea collected in both groups was similar: $3.5 \%$ in the air group and $3.9 \%$ in the $\mathrm{CO}_{2}$ group, with duration of less than 30 seconds (Table III). These events were not clinically significant nor were precise cardiopulmonary resuscitation maneuvers.

The intensity of pain experienced by patients after the colonoscopy was higher in the air group at all cut points

Table II. Collected data during and after colonoscopies

\begin{tabular}{lccc}
\hline & Air & $\mathrm{CO}_{2}$ & $p$ value \\
\hline Propofol & $69.8 \mathrm{mg}$ & $70 \mathrm{mg}$ & 0.676 (NS) \\
Midazolam & $3.13 \mathrm{mg}$ & $3 \mathrm{mg}$ & 0.735 (NS) \\
Sedation level deep/moderate/superficial & $75 \% / 20.6 \% / 4.4 \%$ & $74.5 \% / 22.5 \% / 3 \%$ & 0.720 (NS) \\
Tolerance VG/G/P & $58 \% / 33 \% / 9 \%$ & $69 \% / 22.5 \% / 8.5 \%$ & 0.151 (NS) \\
Cecal intubation time & 6.5 & 6.1 & 0.198 (NS) \\
Total time & 14.2 & 12.7 & 0.341 (NS) \\
Recovery time & 29.5 & 30.6 & 0.466 (NS) \\
Senior endoscopist/Training endoscopist & $71 \% / 29 \%$ & $86 \% / 14 \%$ & 0.003 (S) \\
\hline
\end{tabular}

Time in minutes. Tolerance (VG: very good; G: good; P: poor). NS: not significant. S: significant. 
Table III. Values during the colonoscopy

\begin{tabular}{lccc}
\hline & Air & $\mathrm{CO}_{2}$ & p value \\
\hline Range $\mathrm{CO}_{2} \mathrm{mmHg}$ & $6-50$ & $7-55$ & $\mathrm{NS}$ \\
Episodes $\mathrm{CO}_{2}<30 \mathrm{mmHg}$ & $51 \%$ & $46 \%$ & 0.205 (NS) \\
Minimun mean value $\mathrm{CO}_{2}$ & 21 & 20.4 & $\mathrm{NS}$ \\
Episodes $\mathrm{CO}_{2}>50 \mathrm{mmHg}$ & 0 & $1(55 \mathrm{mmHg})$ & $\mathrm{NS}$ \\
Hypoxemia $(<95 \%)$ & $19 \%$ & $24 \%$ & 0.261 (NS) \\
Apnea episodes & $3.5 \%$ & $3.9 \%$ & 0.886 (NS) \\
\hline
\end{tabular}

$\mathrm{CO}_{2}: \mathrm{CO}_{2}$ in expired air by capnography. $\mathrm{O}_{2}$ : partial pressure oxygen by transdermic pulse oximetry. NS: not significant. S: significant.

tested, reaching statistical significance in the first four time measurements (at 15 minutes, 1, 3 and 6 hours after the scan) and tended to be similar at 24 hours (Table IV). Thirty eight percent of $\mathrm{CO}_{2}$ group patients reported not feeling any pain, value 0 in the VNS at 15 minutes until the completion the colonoscopy compared to $15 \%$ in the air group.

The fact that TE preformed less exploration in the $\mathrm{CO}_{2}$ group (14\% of total) compared to those carried out in the air group (29\%), the group in which pain intensity was higher, prompted us to analyze the possible impact the endoscopic experience could have on the intensity of pain experienced by patients. We found that in all analyzed cutoffs (15 minutes, 1, 3, 6 and 24 hours after colonoscopy) pain intensity was significantly higher in the examinations conducted by the TE compared with those made by the SE. On the other hand, TE scored significantly lower in the EVN when $\mathrm{CO}_{2}$ had been used $(1.72,1.05,0.55,0.27$ and 0.16 at 15 minutes, 1, 3, 6 and 24 hours, respectively) than when air was used (3.95, 3.17, 2.9, 1.39 and 0.48). However, performing a multiple logistic regression to control the effect of endoscopic experiences we found that although both, type of doctors (TE/SE) and type of insufflation gas $\left(\mathrm{CO}_{2} / \mathrm{air}\right)$, influenced the production of pain the odds ratio of the type of gas is greater, a 3.78 compared to 2.15 (95\% CI 2.2 to 6.4). Therefore, after multivariant adjustment for type of doctor (TE $v s$. SE) the differences observed in pain intensity for each group were maintained.

\section{DISCUSSION}

Our study shows that with the use of $\mathrm{CO}_{2}$ gas insufflation during a colonoscopy, patients experienced less pain after the procedure compared with the suffering that was experienced when ambient air was used. This difference is significantly in favor of $\mathrm{CO}_{2}$ at 15 minutes and remains so in the 1, 3 and 6 hours, tending to equalize after 24 hours. In addition, $38 \%$ of patients reported no pain (VSN equals 0 ) at 15 minutes after colonoscopy with $\mathrm{CO}_{2}$ compared with $15 \%$ in the air group.

Because we use moderate or deep sedation in our patients, it was not possible to compare the pain experienced during the colonoscopy, although endoscopists, blinded to
Table IV. Abdominal pain intensity evaluated with visual numeric scale (VNS)

\begin{tabular}{lccl}
\hline Pain score & Air & $\mathrm{CO}_{2}$ & $p$ value \\
\hline 15 minutes & 3.27 & 1.46 & $0.000(\mathrm{~S})$ \\
1 hour & 2.18 & 0.81 & $0.000(\mathrm{~S})$ \\
3 hours & 1.28 & 0.50 & $0.000(\mathrm{~S})$ \\
6 hours & 0.78 & 0.36 & $0.002(\mathrm{~S})$ \\
24 hours & 0.29 & 0.19 & $0.886(\mathrm{NS})$
\end{tabular}

S: significant; NS: not significant.

the type of gas insufflated, tended to regard the patients in the $\mathrm{CO}_{2}$ group with a better tolerance than the air group $(\mathrm{p}$ $=0.151$ ). However, because in the production of abdominal pain during the colonoscopy, besides the insufflation, also is involving the traction exerted on the colon it seems more reliable to assess pain, attributable to the colonic insufflations, the recovery phase in which the traction is no longer present.

In previous studies, although with different pain assessment scales and applied at different times with respect to the performance of the colonoscopy, it was shown that the use of $\mathrm{CO}_{2}$ was associated with less pain during (12) and after to the colonoscopy $(6-9,11-14,18)$. While no group has reported a contrary result, in these studies, the use of $\mathrm{CO}_{2}$ caused significantly less pain compared with air between 10 minutes (9) and 6 hours of a completed colonoscopy $(6-8,11,14)$, although in some cases the difference is not significant one hour later (12) or 6 hours after (18) and in others remains so until 24 hours after the procedure $(6,8)$. Two of these studies performed an abdominal radiograph at the time of completion of the exploration, finding less residual intestinal air with $\mathrm{CO}_{2}$ insufflation $(6,7)$. In a recent meta-analysis (15), with data available from 9 randomized controlled trials comparing $\mathrm{CO}_{2}$ insufflation or air during colonoscopy, calculated "the number needed to treat (NNT)" to prevent one extra person from having discomfort in colonoscopy and the NNT was 7 during the procedure and for after the procedure it was 2 at 1 hour, 3 at 6 hours, and 12 at 24 hours.

In our study, the experienced pain only reached a value greater than 3 after 15 minutes of colonoscopy in the air group. For all other breakpoints in both groups, pain was less than 3, always much smaller and closer to 0 in the $\mathrm{CO}_{2}$ group. Although one might think that a mild pain may have little effect, two studies $(16,17)$ show that as much as $20 \%$ of individuals undergoing screening colonoscopy with ambient air, require more than 24-48 hours of recovery before continuing their daily activity. The use of $\mathrm{CO}_{2}$ may contribute to a faster return to normal activity and thereby help to decrease the indirect costs of colonoscopy. Another benefit we observed in our study, although not quantified, was the realization that the patient who had undergone a colonoscopy with $\mathrm{CO}_{2}$ felt less shame when experiencing 
less flatulence, which made them have an immediate perception of comfort and tolerance to exploration. Both the decrease in pain experienced and the feeling of shame is likely to have a positive impact on the increasing acceptance of colonoscopy, although this aspect could not be confirmed by studies that tried unsuccessfully to find differences in the percentages of patients who said they were willing to accept a colonoscopy of screening of colorectal cancer in the future, few minutes after undergoing a colonoscopy with $\mathrm{CO}_{2}$ or air $(12,14)$.

Certainty of safety is a fundamental aspect when recommending the use of $\mathrm{CO}_{2}$ insufflation during a colonoscopy. Our study includes patients sedated with a combination of midazolam and propofol sedation at moderate (21-23\%) or deep levels $(75 \%)$. It has been recorded all the values of $\mathrm{pO}_{2}, \mathrm{pCO}_{2}$ and $\mathrm{HR}$ before, during and after the procedure. We have not found any other published study, since most of them collect data from patients who have not been sedated or have been superficially sedated $(6-10,12,18)$ or in the case of patients undergoing a colonoscopy with deep sedation using propofol, $\mathrm{pCO}_{2}(14)$ was not collected.

There was no significant difference between the groups with mean values of $\mathrm{pCO}_{2}$ at any time. However, many episodes of hypocapnia were objectified $\left(\mathrm{pCO}_{2}<30\right.$ $\mathrm{mmHg}$ ), in $51 \%$ of patients in the air group and $46 \%$ of patients in the $\mathrm{CO}_{2}$ group, and there were no differences between groups. None of these episodes had clinical consequences. Since patients were sedated and mostly showed good tolerance to the exploration, it does not seem that the decrease in $\mathrm{pCO}_{2}$ can be secondary to a mechanism of hyperventilation. There was only one episode of hypercapnia in a patient from the $\mathrm{CO}_{2}$ group, who reached a $\mathrm{pCO}_{2}$ of $55 \mathrm{mmHg}$, and did not have any symptoms. Episodes of hypoxemia $\left(\mathrm{pO}_{2}<95 \%\right)$ were much less frequent and there was no significant differences between the two groups. In the literature, there are very few studies that have monitored and compared the $\mathrm{pCO}_{2}$ levels like this clinical setting. In one of the first studies (19), there was no difference in the patients' blood $\mathrm{pH}$ before and after undergoing a colonoscopy with $\mathrm{CO}_{2}$, and only a slight increase in the mean partial arterial pressure of $\mathrm{CO}_{2}\left(\mathrm{pCO}_{2}\right)$ in the end, which was not statistically significant and remained within normal limits. In another study (8) patients undergoing a colonoscopy without $\mathrm{CO}_{2}$ or air, were sedated, and a significant decrease in $\mathrm{ETCO}_{2}$ during procedure in both groups were found. It was somewhat less marked in the $\mathrm{CO}_{2}$ group, and attributed to possible hyperventilation of patients during the colonoscopy, as we have seen, it does not be the mechanism involved in decreasing $\mathrm{pCO}_{2}$ that we were objectified also in our sedated patients. Yet another study of the same group (11) showed no differences in $\mathrm{ETCO}_{2}$ during the colonoscopy with air or $\mathrm{CO}_{2}$, but it did picked up a small increase in $\mathrm{ETCO}_{2}$ in patients receiving light sedation compared with patients who were unsedated, regardless of insufflation gas. Finally, other authors (18), have found slightly higher values of transcutaneous $\mathrm{pCO}_{2}$ during colonoscopy in patients without sedation com- pared with those values found before or after the procedure, but within the normal range and without differences between air and $\mathrm{CO}_{2}$ groups.

Therefore, in all these studies, including ours, we cannot find a consistent behavioral pattern of $\mathrm{pCO}_{2}$ during a colonoscopy with $\mathrm{CO}_{2}$. This is probably unrelated to the fact of the use of $\mathrm{CO}_{2}$, and therefore so poorly reproducible. In this sense, the literature does not contain any adverse effects secondary to the $\mathrm{CO}_{2}$ insufflation during the colonoscopy, although studies have excluded patients with severe respiratory diseases or clinical situations that may lead to a decreased ventilation (20).

Hypoventilation or apnea commonly occurs during a colonoscopy with sedation. Capnography is more realiable than pulse oximetry in early detection of respiratory depression in this context (21).

Like other authors, we excluded patients with morbid obesity (BMI > 40), but in assessing the subgroup of patients with BMI between 30 and 39, we did not observe higher levels of $\mathrm{ETCO}_{2}$ and respiratory adverse effect, so probably the use of $\mathrm{CO}_{2}$ can be safe even in morbidly obese subjects when monitored with capnography.

As for the time of cecal intubation and sedation doses used, there was no difference between using $\mathrm{CO}_{2}$ or air, in agreement with other previously published studies $(9,12,14)$ and in disagreement with others that have reported a lesser cecal intubation time $(8,18)$ or lower doses of midazolam in patients who underwent endoscopic submucosal dissection (22). We also found no differences between groups in terms of time spent in the recovery room after the colonoscopy, which was probably due to the high workload of the nurse in charge of this room. Moreover, we found that colonoscopies performed by the TE, were generally associated with increased pain when compared with those practiced by SE, which scored significantly lower pain in the VNS. Besides other factors, we believe that the significantly greater time spent on each colonoscopy by the TE (air group: EF 18.17 minutes/EE 11.58, $\mathrm{CO}_{2}$ group: EF $17.38 / \mathrm{EE} \mathrm{11.90),} \mathrm{most} \mathrm{likely} \mathrm{is} \mathrm{associated} \mathrm{with} \mathrm{a} \mathrm{greater}$ volume of gas insufflated, and is the main cause of the increase of pain, but it was always much lower with the use of $\mathrm{CO}_{2}$. In this context, we have found another advantage of using $\mathrm{CO}_{2}$, which would facilitate the learning of colonoscopy technique as previously noted (23). The advantages of the use of $\mathrm{CO}_{2}$ may be even more striking in endoscopic techniques that are complex and long lasting, such as ERCP, enteroscopy or therapeutic colonoscopies in which the use of $\mathrm{CO}_{2}$ is not only associated with a lower production of abdominal pain but could also facilitate such procedures. In this sense, it has been reported that the use of $\mathrm{CO}_{2}$ allows explore a greater length of small intestine compared with ambient air (24), and it has been suggested that it could facilitate the endoscopic management of iatrogenic colon perforations, contributing to greater hemodynamic stability after perforation compared with that produced during the use of air which originates in a greater and more abrupt pneumoperitoneum (25). 
Our study, conducted in patients undergoing a colonoscopy with deep sedation with monitoring of $\mathrm{pCO}_{2}$, reinforces evidence from previous studies about the significant reduction of abdominal pain, which gets with the use of $\mathrm{CO}_{2}$, from the very first minutes after the colonoscopy, and demonstrates that this benefit is maintained and is safe in patients under deep sedation. It would be desirable in the coming years there were a gradual replacement of ambient air by $\mathrm{CO}_{2}$ gas insufflation in colonoscopy and other endoscopic techniques in the continuous improvement of its quality.

\section{REFERENCES}

1. Rex DK, Johnson DA, Anderson JC, Schoenfeld PS, Burke CA, Inadomi JM. American College of Gastroenterology Guidelines for Colorectal Cancer Screening 2009. Am J Gastroenterol 2009;104:739-50.

2. Ladas SD, Karamanoli G, Ben-Soussan E. Colonic gas explosion during therapeutic colonoscopy with electrocautery. World J Gastroenterol 2007;13:5295-8.

3. Cappell MS, Friedel D. The role of sigmoidoscopy and colonoscopy in the diagnosis and management of lower gastrointestinal disorders: endoscopic findings, therapy, and complications. Med Clin Norte Am 2002;86:1253-88.

4. Williams CB. Who s for CO2? Gastrointest Endosc 1986;32:365-7.

5. Boley SJ, Agrawal GP, Warren AR, Veith FJ, Levowitz BS, Treiber $\mathrm{W}$, et al. Pathophysiologic effects of bowel distension on intestinal blood flow. Am J Surg 1969;117:228-34.

6. Stevenson GW, Wilson JA, Wilkinson J, Norman G, Goodacre RL. Pain following colonoscopy: elimination with carbon dioxide. Gastrointest Endosc 1992;38:564-7.

7. Sumanac K, Zeally I, Fox BM, Rawlinson J, Salena B, Marshall JK, et al. Minimizing postcolonoscopy abdominal pain by using $\mathrm{CO} 2$ insufflation: a prospective, randomized, double blind, controlled trial evaluating a new commercially available $\mathrm{CO} 2$ delivery system. Gastrointest Endosc 2002;56:190-4.

8. Bretthauer M, Thiis-Evensen E, Huppertz-Hauss G, Gisselsson L, Grotmol T, Skovlund E, et al. NORCCAP (Norwegian colorectal cancer prevention): a randomised trial to assess the safety and efficacy of carbon dioxide versus air inssuflation in colonoscopy. Gut 2002;50:604-7.

9. Church J, Delaney C. Randomized, controlled trial of carbon dioxide insufflation during colonoscopy. Dis Colon Rectum 2003;46:322-6.

10. Yasumasa K, Nakajima K, Endo S, Ito T, Matsuda H, Nishida T. Carbon dioxide insufflation attenuates parietal blood flow obstruction in distended colon. Surg Endosc 2006;20:587-94.
11. Brettauer M, Lynge AB, Thiis-Evensen E, Hoff G, Fausa O, Aabakken L. Carbon dioxide insufflation in colonoscopy: safe and effective in sedated patients. Endoscopy 2005;37:706-9.

12. Wong JC, Yau KK, Cheung HY, Wong DC, Chung CC, Li MK. Towards painless colonoscopy: a randomized controlled trial on carbon dioxide-insufflating colonoscopy. ANZ J Surg 2008;78:871-4.

13. Rogers BH. Carbon dioxide for colonoscopy. Gastroenterology 1980;78:1659-60.

14. Riss S, Akan B, Mikola B, Rieder E, Karner-Hanusch J, Dirlea D, et al. CO2 insufflation during colonoscopy decreases post-interventional pain in deeply sedated patients: a randomized controlled trial. Wien Klin Wochenschr 2009;121:464-8.

15. Wu J, Hu B. The role of carbon dioxide insufflations in colonoscopy: a systematic review and meta-analysis. Endoscopy 2012;44:128-36.

16. Ko CW, Riffle S, Shapiro JA, Saunders MD, Lee DS, Tung BY, et al. Incidence of minor complications and time lost from normal activities after screening or surveillance colonoscopy. Gastrointest Endosc 2007;65:648-56

17. Jonas DE, Russell LB, Sandler RS, Chou J, Pignone M. Patients time requirements for screening colonoscopy. Am J Gastroenterol 2007; 102:2401-10.

18. Yamano H, Yoshikawa K, Kimura T, Yamamoto E, Harada E, Kudou $\mathrm{T}$, et al. Carbon dioxide insufflation for colonoscopy: evaluation of gas volume, abdominal pain, examination time and transcutaneous partial CO2 pressure. J Gastroenterol 2010;45:1235-40.

19. Rogers BH. The safety of carbon dioxide insufflation during colonoscopic electrosurgical polipectomy. Gastrointest Endosc 1974;20:115-7.

20. Dellon ES, Hawk JS, Grimm IS, Shaheen NJ. The use of carbon dioxide for insufflation during GI endoscopy: a systematic review. Gastrointest Endosc 2009;69:843-9.

21. Cacho G, Pérez-Calle JL, Barbado A, Lledó JL, Ojea R, FernándezRodríguez CM. Capnography is superior to pulse oximetry for the detection of respiratory depression during colonoscopy. Rev Esp Enferm Dig 2010;102:86-9.

22. Saito Y, Uraoka T, Matsuda T, Emura F, Ikehara H, Mashimo Y, et al. A pilot study to assess the safety and efficacy of carbon dioxide insufflation during colorectal endoscopic submucosal dissection with the patient under conscious sedation. Gastrointest Endosc 2007;65:537-42.

23. Uraoka T, Kato J, Kuriyama M, Hori K, Ishikawa S, Harada K, et al. $\mathrm{CO} 2$ insufflation for potentially difficult colonoscopies: efficacy when used by less experienced colonoscopists. World J Gastroenterol 2009; 15:5186-92.

24. Domagk D, Bretthauer M, Lenz P, Aabakken L, Ullerich H, Maaser $\mathrm{C}$, et al. Carbon dioxide insufflation improves intubation depth in double-balloon enteroscopy: a randomized, controlled, double-blind trial. Endoscopy 2007;39:1064-7.

25. Seebach L, Bauerfeind P, Gubler C. "Sparing the surgeon": Clinical experience with over-the-scope clips for gastrointestinal perforation. Endoscopy 2010;42:1108-11. 